\title{
ENTREVISTA COM STEPHEN J. BALL: UM DIÁLOGO SOBRE JUSTIÇA SOCIAL, PESQUISA E POLÍTICA EDUCACIONAL
}

\author{
JEFFERSON MAINARDES \\ Maria InÊS Marcondes*
}

tephen J. Ball é professor do Instituto de Educação da Universidade de Londres, onde é Karl Manheim Professor of Sociology of Education. Ele é um dos mais eminentes pesquisadores da área de política educacional da atualidade. Suas pesquisas oferecem interessantes recursos intelectuais que permitem compreender como as políticas são produzidas, o que elas pretendem e quais os seus efeitos. Desde o início da década de 1980, Ball vem desenvolvendo pesquisas e publicando livros e artigos sobre temas variados, tais como: teoria da organização escolar, etnografia, micropolítica, mercados educacionais, reformas educacionais, escolha das escolas pelos pais, privatização da educação, performatividade, mudanças discursivas no contexto educacional e escolar, impacto das reformas sobre o trabalho e a identidade dos professores e demais profissionais da educação, redes políticas, entre outros. Esses temas, em geral, são analisados de forma articulada aos conceitos de justiça social, poder, desigualdades sociais, classes sociais e discurso. Os trabalhos de Ball possuem, em geral, uma perspectiva desconstrucionista e as análises usualmente são críticas e fortemente articuladas ao contexto macrossocial. Sua obra é fundamentada teoricamente em uma concepção pluralista, caracterizando-se pelo uso

\footnotetext{
* Doutor em Educação e professor da Universidade Estadual de Ponta Grossa (UEPG). E-mail: jefferson.m@uol.com.br

** Doutora em Ciências Humanas/Educação e professora da Pontifícia Universidade Católica do Rio de Janeiro (PUC-RIO). E-mail: mim@puc-rio.br
} 
de diferentes conceitos e teorias que, em seu conjunto, resultam em análises coerentes e consistentes. Em virtude desta perspectiva pluralista, Ball utiliza contribuições de autores como Foucault, Bourdieu, Bernstein, Weber, entre outros.

Stephen J. Ball é um dos diretores associados do Centre for Critical Education Policy Studies ("Centro de Estudos Críticos de Políticas Educacionais”), do Instituto de Educação da Universidade de Londres. Este Centro congrega pesquisadores interessados em investigar os processos pelos quais as políticas educacionais são formadas, implementadas e experimentadas. As preocupações centrais destes pesquisadores direcionamse às consequências materiais das políticas, em termos de equidade e inclusão. O termo "crítico" sinaliza um compromisso específico com a justiça social. Assim, os pesquisadores desse Centro buscam interrogar, avaliar e analisar políticas em termos de suas contribuiçóes - positivas e negativas - para a realização da justiça social.

Sua obra inclui numerosos livros e artigos. Dentre os principais conceitos e temáticas desenvolvidos por ele destacam-se: a abordagem do ciclo de políticas, micropolítica, performatividade, mudanças discursivas, entre outros, que vêm sendo utilizados no Brasil por diversos pesquisadores. ${ }^{1}$

A entrevista a seguir ${ }^{2}$ foi realizada no dia 11 de setembro de 2007, ocasião em que os entrevistadores participavam da Reunião Anual da British Educational Research Association (BERA) - "Associação Britânica de Pesquisa Educacional” -, realizada no Instituto de Educação da Universidade de Londres. Os entrevistadores acrescentaram notas explicativas e referências bibliográficas, com o intuito de facilitar a compreensão de alguns aspectos da entrevista. Incluiu-se também uma lista das principais obras de Stephen J. Ball e uma relação de seus trabalhos publicados em português.

Entrevistadores (E): Gostariamos de começar apresentando questôes sobre "a abordagem do ciclo de politicas". ${ }^{3}$ Essa abordagem foi formulada na década de 1990 (1992-1994). Você tem algum plano de escrever algo mais sobre essa abordagem?

Stephen J. Ball (SJB): Na realidade, pretendo escrever mais claramente sobre esse tópico, elaborar algumas questóes de que tratei de forma mais condensada em escritos anteriores. $\mathrm{O}$ principal ponto que gostaria de destacar é o de que o ciclo de políticas é um método. Ele 
não diz respeito à explicação das políticas. É uma maneira de pesquisar e teorizar as políticas. Algumas pessoas o leram e interpretaram como se eu estivesse descrevendo políticas e os processos de elaborá-las. O ciclo de políticas não tem a intenção de ser uma descrição das políticas, é uma maneira de pensar as políticas e saber como elas são "feitas", usando alguns conceitos que são diferentes dos tradicionais como, por exemplo, o de atuação ou encenação (enactment). ${ }^{4}$ Quero rejeitar completamente a idéia de que as políticas são implementadas. Eu não acredito que políticas sejam implementadas, pois isso sugere um processo linear pelo qual elas se movimentam em direção à prática de maneira direta. Este é um uso descuidado e impensado do verbo. O processo de traduzir políticas em práticas é extremamente complexo; é uma alternação entre modalidades. A modalidade primária é textual, pois as políticas são escritas, enquanto que a prática é ação, inclui o fazer coisas. Assim, a pessoa que põe em prática as políticas tem que converter/transformar essas duas modalidades, entre a modalidade da palavra escrita e a da ação, e isto é algo difícil e desafiador de se fazer. E o que isto envolve é um processo de atuação, a efetivação da política na prática e através da prática. É quase como uma peça teatral. Temos as palavras do texto da peça, mas a realidade da peça apenas toma vida quando alguém as representa. E este é um processo de interpretação e criatividade e as políticas são assim. A prática é composta de muito mais do que a soma de uma gama de políticas e é tipicamente investida de valores locais e pessoais e, como tal, envolve a resolução de, ou luta com, expectativas e requisitos contraditórios - acordos e ajustes secundários fazem-se necessários.

E: Isso significa que os professores são atores, eles têm histórias, histórias de vida relacionadas à escola, ao currículo...

SJB: E eles trazem suas experiências para este processo ou não. Em alguns casos, pode se tratar de um professor muito inexperiente, que acha muito difícil apropriar-se desse processo de atuação. Este é um processo social e pessoal, mas é também um processo material, na medida em que as políticas têm de ser "representadas" em contextos materiais. Se você tem uma escola com muitos recursos e muito dinheiro, professores muito experientes, alunos muito cooperativos, a "atuação" torna-se um pouco mais fácil do que na situação em que temos alunos com enormes dificuldades de aprendizagem, poucos recursos, instalações precárias, professores muito inexperientes; então, todo 
o processo é diferente. Políticas, principalmente educacionais, são pensadas e em seguida escritas com relação às melhores escolas possíveis (salas de aula, universidades, faculdades), com pouco reconhecimento de variações de contexto, em recursos ou em capacidades locais.

E: Retomando a questão sobre a abordagem do ciclo de politicas, gostaríamos de perguntar algo sobre os dois últimos contextos: o contexto de resultados/efeitos e o contexto de estratégia politica. Muitos pesquisadores, em diferentes paises, têm focalizado apenas os três contextos primários (de influência, produção de texto, contexto da prática). Algumas vezes, não fazem referência aos contextos de resultados e de estratégia politica. Como você avalia essa questão?

SJB: Eu já repensei isso. Não é útil separá-los e eles deveriam ser incluídos no contexto da prática e da influência, respectivamente. Em grande parte, os resultados são uma extensão da prática. Resultados de primeira ordem ${ }^{5}$ decorrem de tentativas de mudar as ações ou o comportamento de professores ou de profissionais que atuam na prática. Resultados de segunda ordem também acontecem, ou pelo menos alguns deles acontecem, dentro do contexto de prática, particularmente aqueles relacionados ao desempenho, a outras formas de aprendizado. Obviamente, outros resultados só podem ser observados a longo prazo e desaparecem dentro de outros contextos de realização. O contexto da ação política, na realidade, pertence ao contexto de influência, porque é parte do ciclo do processo através do qual as políticas são mudadas, ou podem ser mudadas ou, pelo menos, o pensamento sobre as políticas muda ou pode ser mudado. O pensar sobre as políticas e o discurso das políticas podem ser mudados pela ação política. Assim, eles podem ser subsumidos e integrados ao contexto de influência.

E: Realmente, quando abordamos o contexto da estratégia politica, precisamos voltar ao contexto de influência ou outros contextos.

SJB: Os contextos podem ser pensados de outra maneira e podem ser "aninhados" uns dentro dos outros. ${ }^{6}$ Assim, dentro do contexto de prática, você poderia ter um contexto de influência e um contexto de produção de texto, de tal forma que o contexto de influência dentro do contexto da prática estaria em relação à versão privilegiada das políticas ou da versão privilegiada da atuação. Assim, podem existir disputas ou versões em competição dentro do contexto da prática, em diferentes interpretações de interpretações. E, ainda, pode haver 
um contexto de produção de texto dentro do contexto de prática, na medida em que materiais práticos são produzidos para utilização dentro da atuação. Assim, podem existir espaços dentro de espaços. Podemos refletir a respeito das políticas em termos de espaços e em termos de tempo, de trajetórias políticas, movimentos de políticas através do tempo e de uma variedade de espaços. Uma política tem uma trajetória semelhante à de um foguete: decola, atravessa o espaço e depois aterrissa. Algumas vezes, acidenta-se; em outras, atinge uma realização espetacular, mas move-se através do tempo e, algumas vezes, simplesmente desaparece. As políticas desaparecem no decorrer do tempo ou, algumas vezes, leva muito tempo para elas se tornarem integradas. Algumas vezes, elas são apressadas ou atrasadas. É necessário pensar sobre a velocidade das políticas, é necessário ter a dimensão do tempo, bem como do espaço.

E: Gostaríamos de ouvir sua posição com relação à pesquisa critica. Em sua opinião, o que você considera pesquisa crítica e qual o papel do pesquisador na pesquisa crítica?

SJB: Para mim, toda pesquisa é pesquisa crítica. Mas suponho que uma definição poderia ser a pesquisa que tem o poder e a justiça social como conceitos-chave. Assim, uma perspectiva crítica é uma necessidade inevitável, se estamos tentando entender como o poder funciona, porque você somente pode abordar o poder desenvolvendo um sentido de seus efeitos e de suas inadequações. E, quando abordamos o poder, sempre queremos perguntar como as pessoas se constituem, se produzem de forma diferente. O que é excluído pelo trabalho com relação ao poder? Isso frequentemente nos leva a questôes sobre justiça social. Isso faz sentido?

E: No Brasil, até o momento presente, há pouca literatura e poucas discussóes sobre justiça social. Trata-se de um conceito que precisariamos aprofundar. Como você conceitua justiça social?

SJB: Suponho que eu iria preferir trabalhar com um conceito de poder, apesar de que a vantagem do conceito de justiça social é de que é um conceito inclusivo, que não é específico à raça, classe, deficiência ou sexualidade; abarca uma concepção ampla de questôes de equidade, oportunidade e justiça. É maleável, tem uma gama ampla de aplicação. Alerta o pesquisador para as variadas maneiras em que a opressão pode funcionar em uma variedade de formas e pode atuar sobre as pessoas 
de diversas maneiras através de seu gênero, posição de classe, sexualidade ou seus graus de habilidade, bem como através de interrelaçôes complexas entre esses fatores. Há vantagens nesse sentido. Inevitavelmente, há desvantagens e há, de certa maneira, uma falta de precisão teórica. Existe uma resposta muito interessante ao trabalho de Sharon Gewirtz e Allan Cribb ("Plural conceptions of social justice: implications for policy sociology", Journal of Education Policy, 2002), que foi escrita por Terri Seddon, cujo título é "Framing justice: challenges for research", que também foi publicada no Journal of Education Policy (v. 18, n. 3, 2003). Ela faz algumas críticas úteis ao conceito de justiça social, mas de forma muito positiva, de forma muito construtiva. Gosto da maneira como Nancy Fraser usa o conceito, enfatizando o que ela chama de "políticas de distribuiçãao" e "políticas de reconhecimento". 7 O conceito básico que sustenta tudo é o conceito de poder. Assim, eu vejo a justiça social através da opressão de poder, vejo as políticas de distribuição e reconhecimento em termos de lutas de poder. Ambos lutam pelo controle de bens e pelo controle dos discursos. As políticas são investidas de, ou formadas a partir de ambos os aspectos de disputas, em termos de vantagens sociais e de legitimidade social; o que pode ser considerada uma "boa" política e quais interesses são servidos pela definição do que seja considerado "bom".

E: Na introdução do livro Social justice, education and identity (Routledge, 2003), Carol Vincent apresentou uma sintese muito interessante sobre o conceito de justiça social. Qual a relevância desse conceito?

SJB: Tem sido estrategicamente um conceito muito bem sucedido de várias maneiras, no sentido de que, na década de 1980 particularmente, havia uma enorme fragmentação em pesquisa social crítica; havia marxistas que faziam seu trabalho, havia as feministas, havia os estudos sobre deficiência, estudos sobre sexualidade, e essas coisas estavam todas indo em diferentes direções e não havia muito diálogo entre elas. E até certo ponto - não estou dizendo que todos esses problemas foram resolvidos -, mas a justiça social ofereceu um espaço de diálogo em que essas áreas de interesse e foco puderam se juntar. Não estou dizendo que é uma solução perfeita, mas ofereceu um espaço comum.

E: Você poderia comentar a sua opinião sobre a "desconstrução", que parece algo muito presente em suas pesquisas? 
SJB: Não vejo muita vantagem em tentar dizer às pessoas o que elas deveriam pensar ou o que deveriam fazer. Isto é tanto intelectualmente arrogante, como algo sem sentido. O que estou tentando fazer através de meu trabalho é dar ferramentas às pessoas para que elas pensem critica e "alternativamente" - conceitos, idéias e abordagens com as quais possam fazer coisas. Isso pode empoderar as pessoas a pensarem por elas mesmas. Este é o objetivo da atividade intelectual. Eu não quero chegar a conclusões que as pessoas depois possam levar com elas e dizer "ah, OK - agora eu sei, não tenho mais que pensar a respeito disso". Quero que as pessoas tirem suas próprias conclusões, pensem por si mesmas. Mas, além disso, a análise social é sempre parcial, é sempre inadequada, a análise social é sempre um fracasso de muitas maneiras. Tudo o que é possível são alguns insights úteis, alguns tijolos nas paredes, algumas peças pequenas de conhecimento estratégico.

E: Isso é interessante porque, no Brasil, temos muitos problemas sociais e desigualdades profundas. Temos problemas tão prementes em nosso sistema educacional que somos algumas vezes levados a pensar muito nas questôes práticas. Se não dizemos nada construtivo, é possivel considerar que não estamos contribuindo para uma mudança positiva.

SJB: Talvez, mas a outra coisa que me preocupa é que obtemos muitas soluçóes, muitas pessoas têm muitas soluções que não parecem ter muito impacto no mundo real. E, freqüentemente, em trabalhos acadêmicos, as conclusôes são uma forma de "performatividade": apresentam-se conclusôes como uma maneira de demonstrar o valor de seu texto, seu valor agregado pessoal ao grande projeto iluminista. Seria mais honesto, realista e útil se mais pesquisadores e acadêmicos adotassem uma posição modesta e tentassem construir, desenvolver gradualmente, adicionar, acumular trabalhos que fornecessem um conjunto de idéias às quais as pessoas pudessem recorrer com relação à prática. Mas, em vez disso, todos querem "conclusões", querem clareza, certeza e fechamento. Querem se fazer relevantes. Querem se tornar comensuráveis dentro das normas da performance em pesquisa.

E: Em algum dos seus textos você critica a forma pragmática que caracteriza a pesquisa realizada no Reino Unido. Em teses de doutorado, no Reino Unido, por exemplo, é comum encontrarmos recomendaçôes nas conclusões. Você acha que os pesquisadores britânicos são mais pragmáticos do que pesquisadores de outros paises? 
SJB: Eu penso que sim. Mas talvez eu tenha um problema. Nunca acho que chego a um ponto no qual eu tenho recomendações a fazer, a não ser "talvez devêssemos refletir melhor a respeito disso". E, normalmente, o que estou tentando fazer é desconstruir o senso comum correntemente em uso, ao invés de oferecer um novo tipo de senso comum.

E: Nesse sentido, parece que existem diferenças entre as suas idéias e as idéias de Sharon Gewirtz. Por exemplo, em um capitulo do livro editado por Carol Vincent (Social justice, education and identity), Sharon Gewirtz e Allan Cribb (2003, p. 21) dizem: "Não é suficiente simplesmente identificar tensóes e dilemas que estão embutidos no trabalho daqueles que estão na prática, ou fatores contextuais que dão forma ou estabelecem limites ao que fazem, ou documentar os processos de reprodução social e cultural. Se tomamos conceitos plurais de justiça com seriedade, então precisamos assegurar que nosso trabalho consista numa ajuda prática àqueles que estão lutando para fazer o melhor, no sentido de fazer avançar a causa da justiça social em circunstâncias adversas".

SJB: Bem, voltamos para o significado que damos ao termo prático. Quero dizer, se eu fosse cínico, eu diria que essa é uma afirmação performativa. Precisamos nos assegurar de que nosso trabalho fornece ajuda prática às pessoas que estão lutando para fazer o melhor possível. $\mathrm{O}$ que isso significa? Como nosso trabalho pode oferecer ajuda prática no sentido que é especificado aqui como distinto da idéia de identificar tensões e dilemas? Essa afirmação sugere que deveríamos dizer às pessoas o que fazer, ou como fazer melhor as coisas, e como sabemos isso? Como sabemos o que é melhor? Como podemos dizer o que é melhor? Talvez devêssemos estar apoiando as pessoas em situações práticas a discutir e debater o que significa o "melhor".

E: Sabemos que é uma questão difícil, mas como Bernstein responderia a essa pergunta? Ele concordaria com você ou diria que é importante pensar em resultados práticos?

SJB: Ele também percebia seu trabalho como o desenvolvimento de um conjunto de ferramentas, como maneiras de pensar sobre os sistemas de mensagem da educação - ele queria mudar o foco do problema de pesquisa sociológica na educação. Sua preocupação era com os aspectos intrínsecos do discurso pedagógico, não "o que é transmitido", mas com o dispositivo pedagógico, a voz, que estrutura e organiza 
o conteúdo e a distribuição do que está sendo transmitido. Ele estava tentando desenvolver um modelo que relacionasse estes sistemas de mensagem às transmissões da educação escolar e às diferentes regras de reconhecimento e realização, e que poderia, assim, explicar as instituiçôes educacionais como geradoras de desigualdade. Sua abordagem sugere uma concepção completamente diferente da reforma educacional ou do objeto de reforma e, nesse sentido, é muito prática.

E: Isso é muito interessante. No livro Tribute to Basil Bernstein (IoE, 2001), há um texto de Sally Power em que ela comenta sobre as quatro coisas que aprendeu com Bernstein. Uma delas é que as análises deste autor encorajam as pessoas a compreenderem o mundo, não necessariamente a mudá-lo.

SJB: Mas, como se diz, não existe nada mais prático do que uma boa teoria. Considerações sobre maneiras de organizar como pensamos sobre problemas são o primeiro passo na direção de abordá-los de forma diferente. Isto é, começar por pensar como o problema que estamos abordando é construído; como algo vem a ser percebido como um problema que necessita de políticas. E, neste caso, a ciência social é tanto o problema quanto a solução - se posso colocar as coisas dessa maneira. Isto é o que Bernstein estava sugerindo à sua maneira, mas também o que Michel Foucault estava abordando constantemente, isto é, a maneira como as Ciências Sociais fornecem ferramentas que organizam formas de pensar sobre problemas sociais e está implicada no gerenciamento das populações. Uma das coisas que está incrustada na praticalidade das Ciências Sociais, através da pressão sobre os pesquisadores educacionais para fazerem recomendações para políticas, é que estamos contribuindo para regimes de disciplina. Estamos tornando as populações categorizáveis. Estamos estabelecendo normas para o comportamento correto, estabelecendo padrões de "boa" prática, definindo a "melhor" prática. Este é um empreendimento moral tanto quanto científico! Podemos nos perceber abordando questôes de desigualdade, mas também fazemos parte da governamentalidade, da produção de conhecimento que permite aos indivíduos governarem-se a si mesmos.

E: Gostaríamos de perguntar algo sobre a relação entre a pesquisa acadêmica, políticas e práticas. Neste Congresso (BERA Conference, 2007), alguns pesquisadores argumentaram que a pesquisa deve ou pode informar a prática e as politicas. No Brasil, em termos da teoria de Bernstein, os 
campos oficiais e pedagógicos estão normalmente separados, apenas raramente funcionando em conjunto. Por que muitos pesquisadores britânicos estão tão preocupados com a funcionalidade da pesquisa educacional?

SJB: Isso tem parcialmente a ver com a história pragmática das Ciências Sociais, mas também é um fenômeno recente. No Reino Unido, faz parte da visão geral de mundo do New Labour (Novo Trabalhismo), que envolve um compromisso com políticas baseadas em evidências. ${ }^{8}$ Trata-se de um compromisso retórico, no sentido de que o governo "escolhe" as evidências que mais se adaptam às suas preferências políticas. Porém, ser relevante para as políticas é atraente para muitos cientistas sociais britânicos e muitos buscam orientar sua pesquisa para problemas práticos identificados pelo governo. A idéia de pesquisa como "evidência" para as políticas é também usada como dispositivo para disciplinar a pesquisa, é usada para selecionar tipos particulares de pesquisa para financiamento, para privilegiar determinados tipos de pesquisa em detrimento de outros. É uma maneira de excluir da pesquisa certas questões, tópicos e vozes.

E: É uma disputa por influências? É algo bastante competitivo, não é?

SJB:: Sim, certamente há competição para influenciar e ser ouvido. Competição para ter acesso a comitês-chave para falar de pesquisa, para "vender" idéias para políticas - um tipo de "empreendedorismo para políticas". Este é um novo tipo de carreira para acadêmicos.

E: É possivel observar, a partir da leitura do seu artigo com Sharon Gewirtz ("From welfarism to new-managerialism: shifting discourses of school headship in the education marketplace" - Discourse, 2000), que as pessoas podem incorporar certos discursos no decorrer do tempo. A leitura desse artigo nos permite apreender melhor o que está acontecendo, mas não são indicadas formas ou estratégias de como isso poderia ser mudado. O que é possivel localizar são idéias importantes e poderosas para compreender discursos e práticas em mutação. E essa uma leitura adequada?

SJB: Sim, é o primeiro passo, mas é um passo necessário. Sem a compreensão da situação, não temos nenhuma possibilidade de agir estrategicamente, não se pode ir a nenhum lugar. Por outro lado, recorrendo ao título de outro trabalho meu - Captured by discourse ("capturado pelo discurso"9) -, estamos sempre operando dentro do discurso e, talvez, você possa fazer coisas interessantes e produtivas dentro do discurso, mas ainda estamos limitados em termos de possibilidades 
para pensar de forma diferente. Podemos pensar apenas dentro das possibilidades do discurso, e apenas pensar dentro da maneira em que problemas são produzidos pelo discurso. trabalhos?

E: Você poderia falar mais sobre o pluralismo teórico presente em seus

SJB: A questão central é que toda teoria é, por definição, inadequada. Toda teoria é limitada pelas posições que assume, as pré-concepçôes dentro das quais opera. A teoria frequentemente reivindica ser capaz de nos explicar o mundo todo, mas inevitavelmente falha, e a maior parte das teorias nos diz algumas coisas úteis sobre partes do mundo. Então, eu parto até certo ponto da idéia de que, se você quiser desenvolver uma análise mais coerente e articulada do mundo, precisamos, de fato, de diferentes tipos de teoria. Por exemplo, a maior parte das teorias trabalha - com a exceção de Bourdieu, eu suponho ou a partir de uma posição de estrutura, ou de uma posição de agência (ação humana), ${ }^{10}$ privilegiando uma em detrimento da outra. Assim, se você quiser entender agência, a não ser que você queira reduzi-la sempre a determinações da estrutura, você precisa de uma teoria diferente de agência para contrastar com sua teoria de estrutura. Uma das atraçôes de Bourdieu é que ele de fato tenta desconstruir esse binômio e busca trabalhar de maneira a combinar as possibilidades de agência e estrutura em um mesmo modelo, e eu acho isso muito atraente. Mas você pode expandir isso para pensar a respeito de como outras partes do mundo funcionam, e que você realmente necessita, como Michel Foucault sugeriu, de uma caixa de ferramentas de teorias. Uma das coisas significativas sobre Bourdieu e Foucault é que nenhum dos dois possui uma teoria social, no sentido em que Marx ou Durkheim têm. Eles não nos oferecem uma teoria totalizante que nos diz como o mundo funciona.

\section{$\mathrm{E}:$ Eles têm conceitos?}

SJB: Eles têm conceitos, eles têm conceitos práticos e poderosos. Algumas vezes, as pessoas dizem que eu sou foucaultiano. Não sou foucaultiano em pelo menos dois sentidos - em meus métodos sou bastante modernista reconstruído, mais do que um pós-estruturalista. Contudo, em segundo lugar, não há nada que seja foucaultiano. Não existe uma posição coerente ou espaço teórico que seja a posição de Foucault. O próprio Foucault não tentou criar uma posição coerente a 
partir da qual falasse - mas, em um sentido mais simples, acredito também que é necessário mais de uma teoria para fazer-se sentido do mundo social; apesar de que, se você juntar vários tipos diferentes de posiçôes teóricas, você precisa estar consciente do que está fazendo. Não podemos apenas juntar teorias sem estarmos conscientes de que podem ocorrer problemas em termos de suas relaçôes ou contradições ontológicas e epistemológicas. Temos que utilizá-las com um sentido de autoconsciência reflexiva. E, novamente, Bourdieu escreveu sobre isso de formas interessantes. Ele estava consciente disso, mas também é importante reconhecer que, na micropolítica da academia, dentro da qual o conhecimento teórico é separado em paradigmas que competem entre si, existe uma tendência em exagerar as diferenças entre os teóricos. E eu estou interessado em enfatizar os aspectos comuns ao invés das diferenças. Bourdieu fala, em alguns de seus livros, a respeito de perceber a si próprio, assumindo algumas das preocupações primárias de Weber. Assim, ele não se vê como um tipo de teórico inteiramente diferente de Weber. Muitas de suas idéias em relação ao livro Distinction: a social critique of the judgement of taste, ${ }^{11}$ seu livro sobre capital cultural e de classe, tem elementos weberianos muito fortes e há outros aspectos de seu trabalho, em termos das noçôes de campo e poder, que possuem aspectos weberianos muito fortes também. Há também alguns paralelos epistemológicos entre Bourdieu e Foucault, em termos de suas práticas e conhecimento acadêmico. Foucault foi o patrocinador de Bourdieu no Collège de France e as pessoas tendem a esquecer que Foucault tinha grande respeito por Bourdieu e vice-versa. E, é claro, indo em outra direção, Althusser foi professor de Foucault e eu acho que existem ecos interessantes do trabalho de Althusser em Foucault. Assim, eu tendo a me interessar pela maneira como as teorias se relacionam, ao invés do que pelas coisas que as separam. Podemos contar diferentes histórias teóricas, podemos contar histórias sobre quão diferentes as pessoas são, mas você também pode contar histórias de como elas podem estar dizendo coisas semelhantes ou relacionadas. Bourdieu, Weber, Foucault, Althusser e Bernstein eram pensadores de mente aberta, ao invés de fechadas, e não se consideravam fechados a outras influências.

E: Professor Ball, agradecemos imensamente pela entrevista. 


\section{Notas}

1. A esse respeito, consultar em <http://www.uepg.br/gppepe > as indicações de trabalhos de pesquisadores brasileiros que têm utilizado as idéias de Ball.

2. A versão do inglês para o português foi feita por Maria Cristina Nogueira e revisada por Maria Inês Marcondes.

3. A respeito da referida abordagem, ver Bowe et al. (1992), Ball (1994) e Mainardes (2006).

4. Originalmente, o professor Ball empregou o termo "enactment". Tradicionalmente, esta palavra tem sido usada no contexto legal para descrever o processo de aprovação de leis e de decretos. Na entrevista, Ball usou a palavra no sentido teatral, referindo-se à noção de o ator possui um texto que pode ser apresentado/representado de diferentes formas. O texto, no entanto é apenas uma pequena parte (porém, uma parte importante) da produção. Ball usou este termo para indicar que as políticas são interpretadas e materializadas de diferentes e variadas formas. Os atores envolvidos (no caso, os professores) têm o controle do processo e não são "meros implementadores" das políticas.

5. Nas formulações de Stephen Ball, efeitos de primeira ordem referem-se a mudanças na prática ou na estrutura e são evidentes em lugares específicos ou no sistema como um todo. Os efeitos de segunda ordem referem-se ao impacto destas mudanças nos padrões de acesso social, oportunidade e justiça social.

6. Bob Lingard considera que os três contextos primários do ciclo de políticas (contexto de influência, produção de texto, contexto da prática) têm paridade de forças, o que configura uma forma útil de "reconceitualizar aquilo que a literatura tradicional das políticas considera uma relação linear de cima para baixo entre a produção e a implementação de políticas" (Lingard, 2004, p. 73)

7. Cf. Fraser (1997).

8. Para se obter um panorama da discussão sobre a prática baseada em evidências, ver Hammersley (2007), Thomas e Pring (2007) e Macnab e Thomas (2007).

9. Trata-se do artigo "Captured by the discourse: issues and concerns in researching parental choice”, em co-autoria com Sharon Gewirtz (Ball \& Gewirtz, 1994).

10. O debate em torno da influência da estrutura (structure) ou da ação humana (agency) sobre o pensamento e comportamento humanos é um das questôes centrais das Ciências Sociais. Neste contexto, "agency" refere-se à capacidade humana individual de agir independentemente e fazer suas próprias escolhas. "Structure" refere-se a fatores, tais como: classe social, religião, gênero, etnia, costumes etc., os quais parecem limitar ou influenciar as oportunidades que os indivíduos têm.

11. Versão em português: Distinção: crítica social do julgamento (Zouk, 2007).

\section{Referências}

\section{BALL, S.J. Education reform: a critical and post-structural approach. Buckingham: Open University Press. 1994.}

Educ. Soc., Campinas, vol. 30, n. 106, p. 303-318, jan./abr. 2009

Disponível em <http://www.cedes.unicamp.br> 
BALL, S.J.; GEWIRTZ, S. Captured by the discourse: issues and concerns in researching parental choice. British Journal of Sociology of Education, London, v. 14, n. 1, p. 63-79, 1994.

BOURDIEU, P. Distinção: crítica social do julgamento. Porto Alegre: Zouk, 2007.

BOWE, R.; BALL, S.; GOLD, A. Reforming education \& changing schools: case studies in Policy Sociology. London: Routledge, 1992.

LINGARD, B. É e não é: globalização vernacular, política e reestruturação educacional. In: Burbules, N.; Torres, C.A. Globalização e educação: perspectivas críticas. Porto Alegre: ARTMED, 2004, p. 59-76.

FRASER, N. Justice interruptus: critical reflections on the "Postsocialist" condition. London: Routledge, 1997.

HAMMERSLEY, M. Educational research and evidence-based practice. London: Sage, 2007.

MACNAB, N.; THOMAS, G. A prática baseada em evidências na educação. Pátio, Porto Alegre, n. 41, fev./abr. 2007.

MAINARDES, J. Abordagem do ciclo de políticas: uma contribuição para a análise de políticas educacionais. Educação \& Sociedade, Campinas, v. 27, n. 94, jan./abr. 2006.

THOMAS, G.; PRING, R. Educação baseada em evidências: a utilização dos achados científicos para a qualificação da prática pedagógica. Porto Alegre: ARTMED, 2007.

Principais obras de Stephen J. Ball:

Beachside comprehensive: a case-study of secondary schooling (Cambridge, 1981).

The micro-politics of the school: towards a theory of school organization (Routledge, 1987).

Teachers' lives and careers (organizado por Stephen J. Ball e Ivor F. Goodson) (Falmer, 1985). 
Foucault and education: disciplines and knowledge (Routledge, 1990). Politics and policy making in education: explorations in policy sociology (Routledge, 1990).

Reforming education and changing schools: case studies in policy sociology (organizado com Richard Bowe) (Routledge, 1992).

Education reform: a critical and post-structural approach (Open University Press, 1994).

Markets, choice and equity in education (organizado com Sharon Gewirtz e Richard Bowe) (oup, 1995).

Education policy and social class: the selected works of Stephen J. Ball (Routledge, 2006).

Education Plc: understanding private sector participation in public sector education (Routledge, 2007).

The education debate (Policy Press, 2008).

Textos de Stephen J. Ball publicados em português:

Mercados educacionais, escolha e classe social: o mercado como uma estratégia de classe. In: Gentili, P. Pedagogia da exclusão: crítica ao neoliberalismo em educação. Petrópolis: Vozes. 1995. p. 196-227.

Cidadania global, consumo e política educacional. In: Sisva, L.H. A escola cidadã no contexto da globalização. Petrópolis: Vozes, 1998. p. 121137.

Diretrizes políticas globais e relações políticas locais em educação. Currículo Sem Fronteiras, v. 1, n. 2, p. xxvii-xliii, 2001. Disponível em: <www.curriculosemfronteiras.org >

Reformar escolas/reformar professores e os terrores da performatividade. Revista Portuguesa de Educação, Braga, v. 15, n. 2, p. 3-23, 2002. Disponível em: <www.redalyc.org>

Stephen Ball e a educação (entrevista a Lucíola Licínio de C. P. Santos). Educação em Revista, Belo Horizonte, n. 40, p. 11- 25, dez. 2004. 
Performatividade, privatização e o pós-Estado do Bem-Estar. Educação \& Sociedade, Campinas, v. 25, n. 89, p. 1105-1126, set-/dez. 2004. Disponível em: <www.scielo.br/es>

Profissionalismo, gerencialismo e performatividade. Cadernos de Pesquisa, São Paulo, v. 35, n. 126, p. 539-564, 2005. Disponível em: $<$ www.scielo.br/cp>

Educação à venda. Coleção Discursos. Cadernos de Políticas Educativas. Mangualde: Ediçôes Pedago, 2005.

Sociologia das políticas educacionais e pesquisa crítico-social: uma revisão pessoal das políticas educacionais e da pesquisa em política educacional. Currículo Sem Fronteiras, v. 6, n. 2, p. 10-32, jul./dez. 2006. Disponível em <www.curriculosemfronteiras.org >

Discursos da reforma educacional no Reino Unido e nos Estados Unidos e o trabalho dos professores (em co-autoria com Meg Maguire). Práxis Educativa, Ponta Grossa, v. 2, n. 2, p. 97 - 104, jul.-dez. 2007. Disponível em: <http://www.uepg.br/praxiseducativa> 